\title{
Impacts of aerosol direct effects on tropospheric ozone through changes in atmospheric dynamics and photolysis rates
}

Jia Xing et al.

Correspondence to: Shuxiao Wang (shxwang@tsinghua.edu.cn)

The copyright of individual parts of the supplement might differ from the CC BY 3.0 License. 


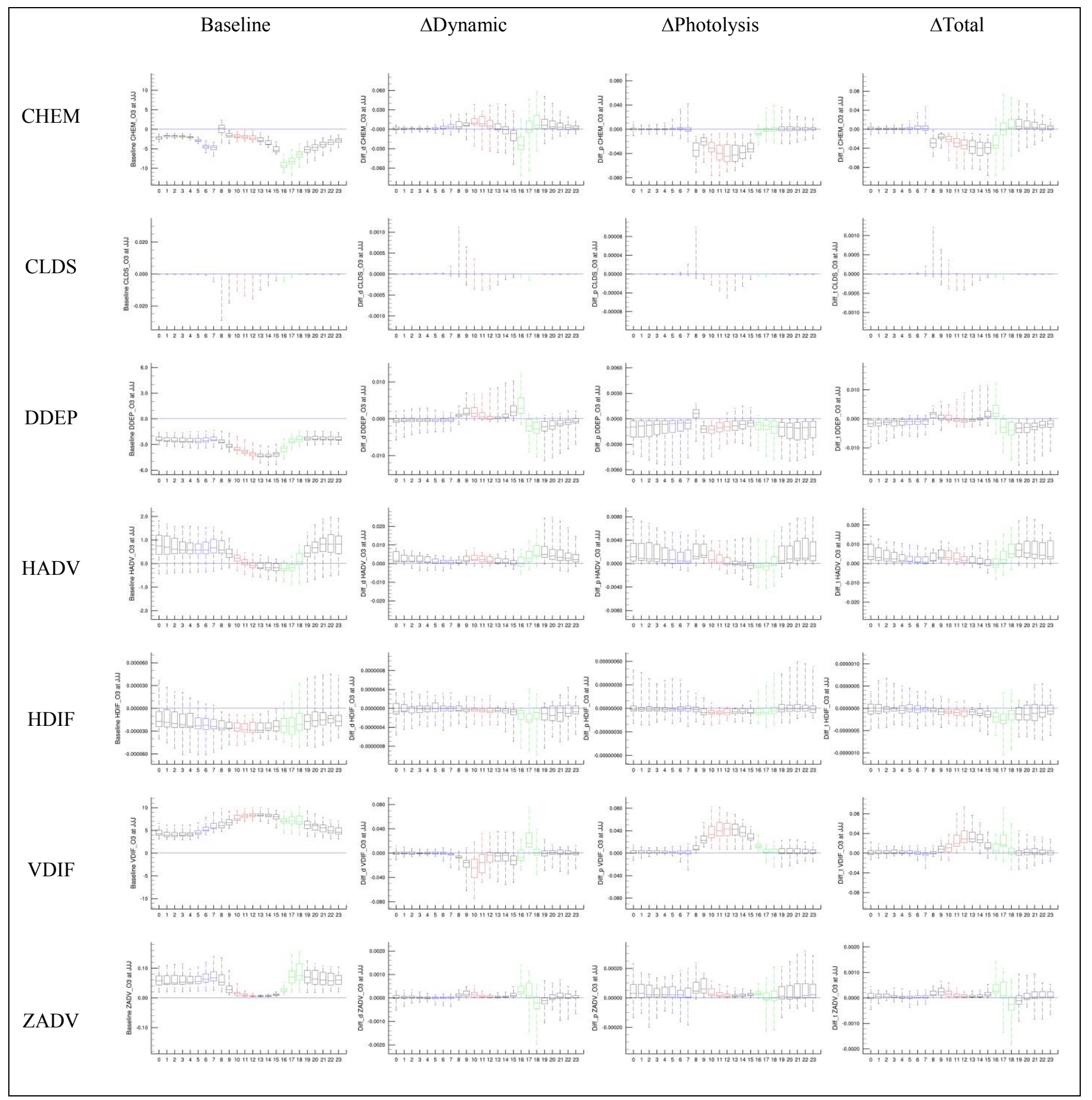

(a) January 


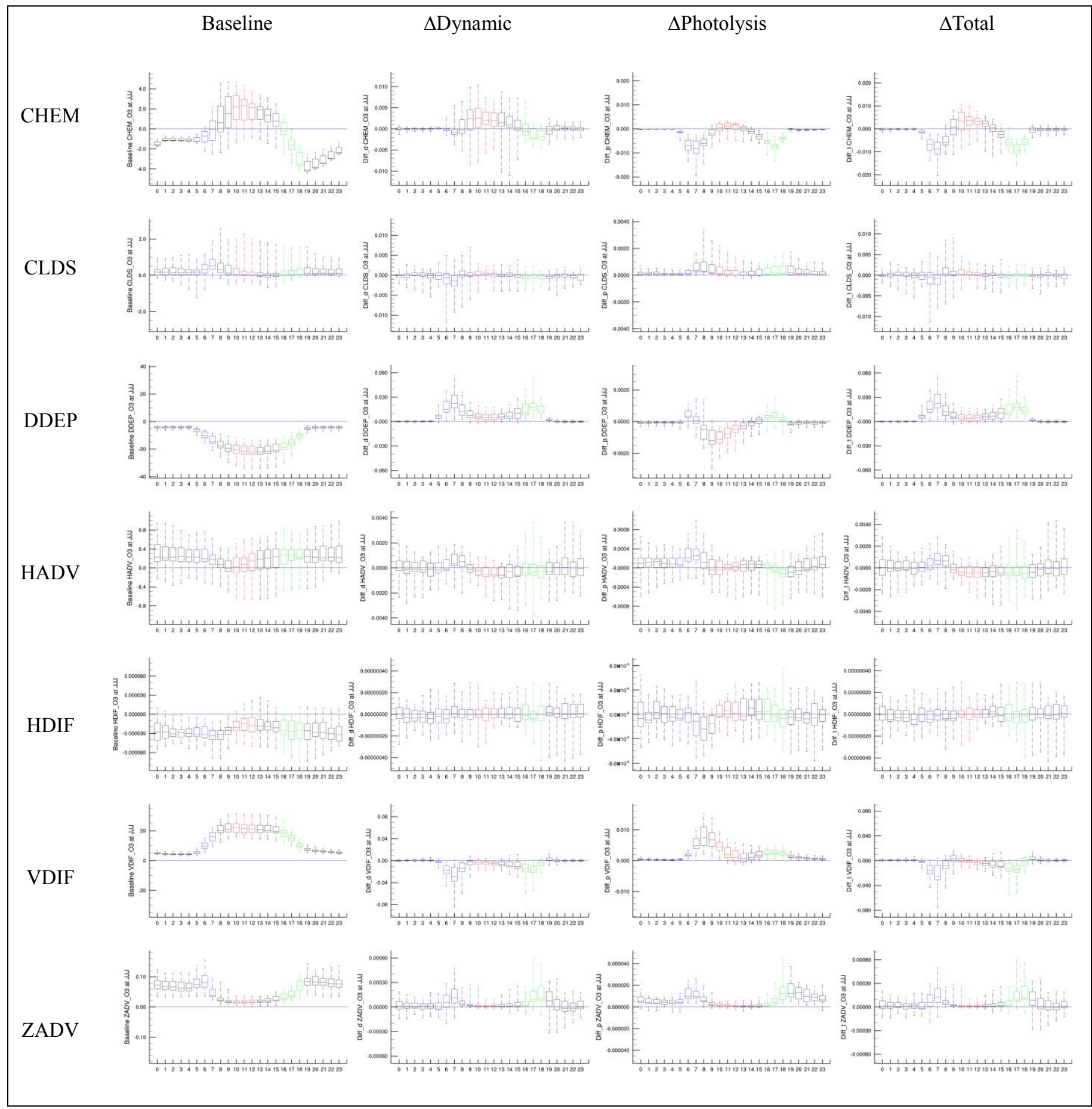

(b) July

Figure S1 Diurnal variation of integrated process contributions to surface $\mathrm{O}_{3}$ concentration in JJJ (a: January; b: July; The calculation is based on the average of grid cells in JJJ; a. Baseline is the simulated $\mathrm{O}_{3}$ in SimBL, unit: $\mathrm{ppb} \mathrm{hr}^{-1}$; b. $\Delta$ Dynamic is the difference in normalized IPRs between SimSF and SimNF, unit: $\mathrm{hr}^{-1}$; d. $\triangle$ Photolysis is the difference in normalized IPRs between SimNF and SimBL, unit: $\mathrm{hr}^{-1}$; c. $\Delta$ Total is the difference in normalized IPRs between SimSF and SimBL, unit: $\mathrm{hr}^{-1}$, colored bars represent three periods of early morning (blue), noon (red), and late afternoon (green)) 


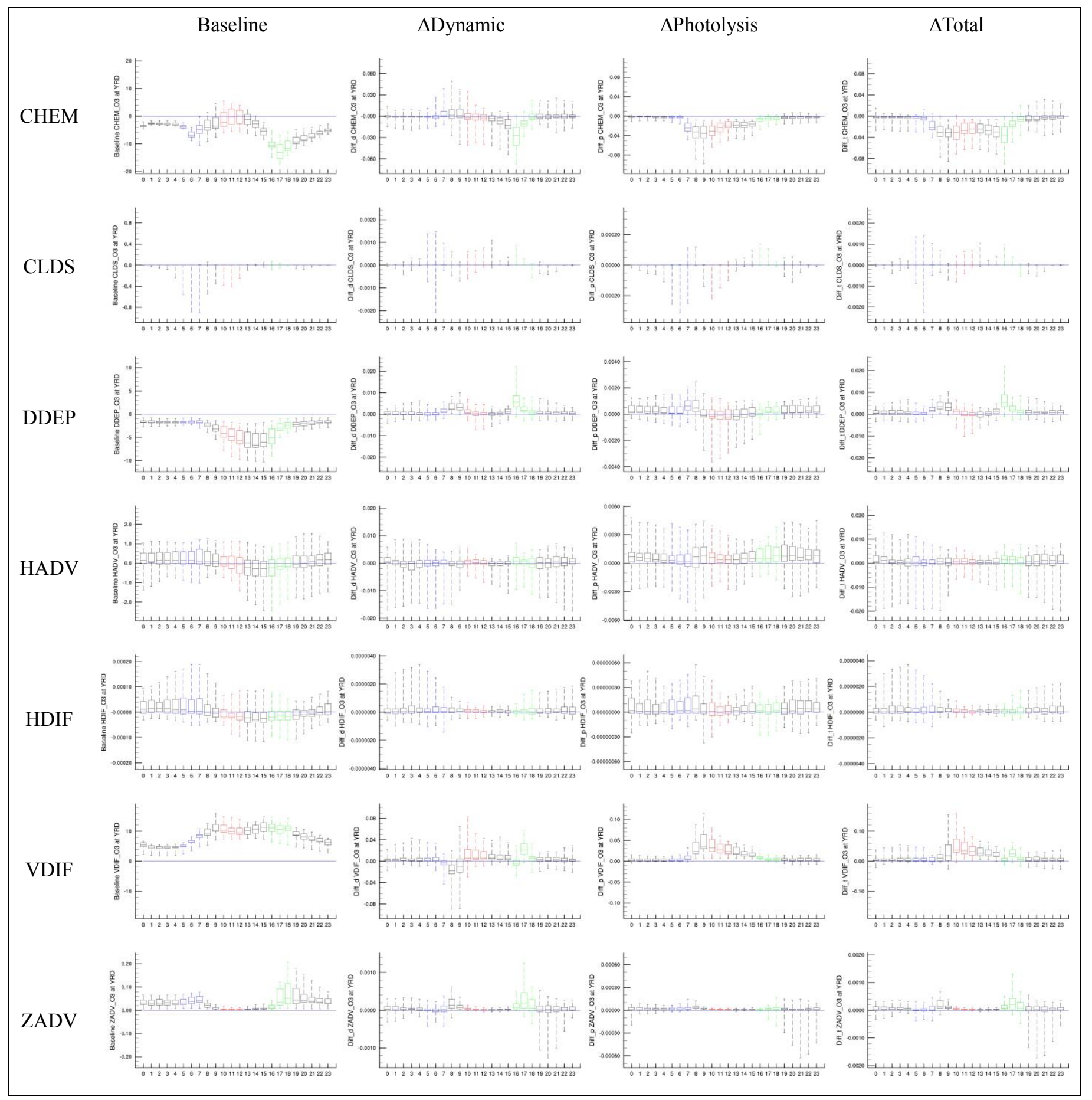

(a) January 


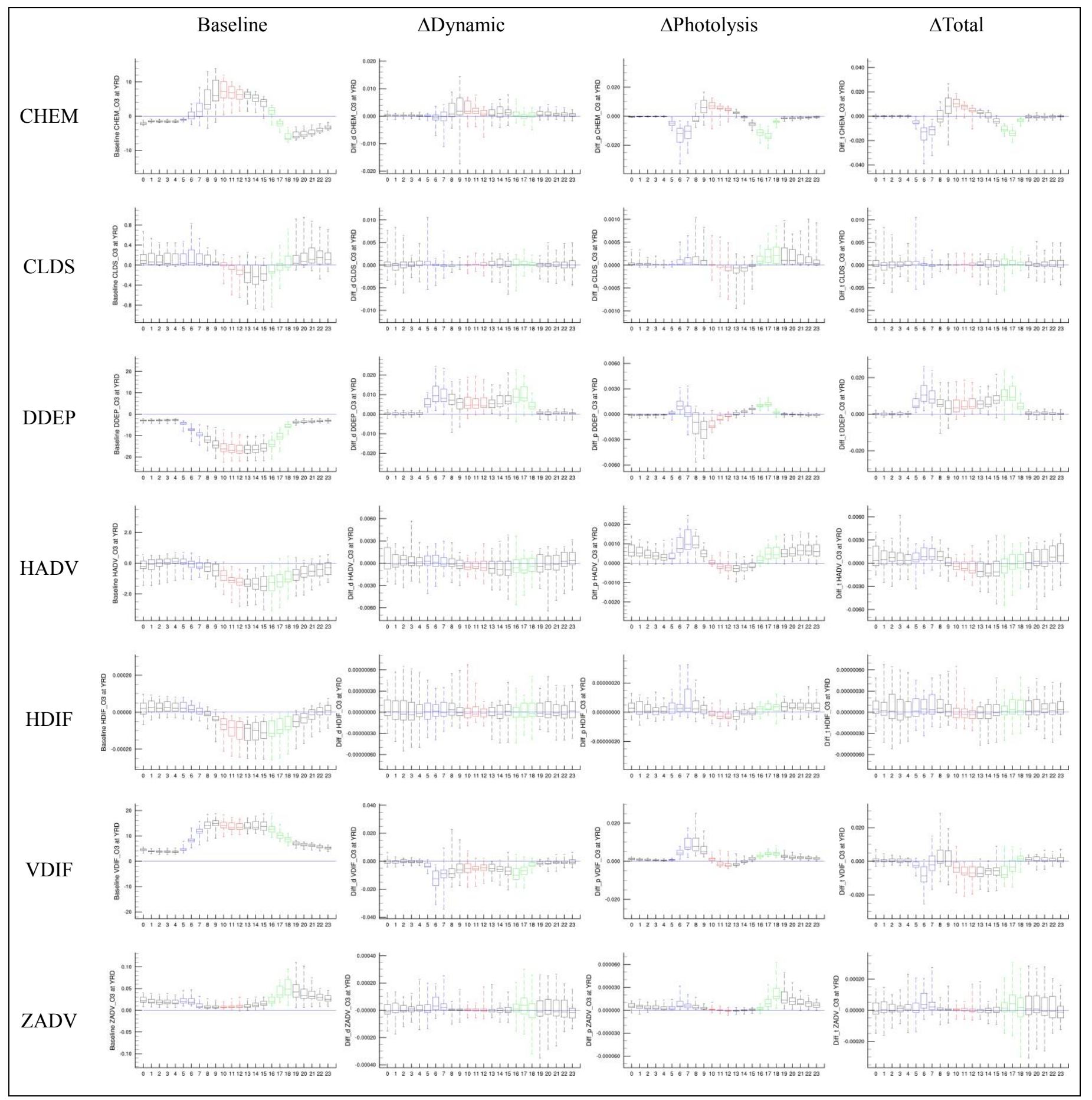

(b) July

Figure S2 same as Figure S1, but in YRD 


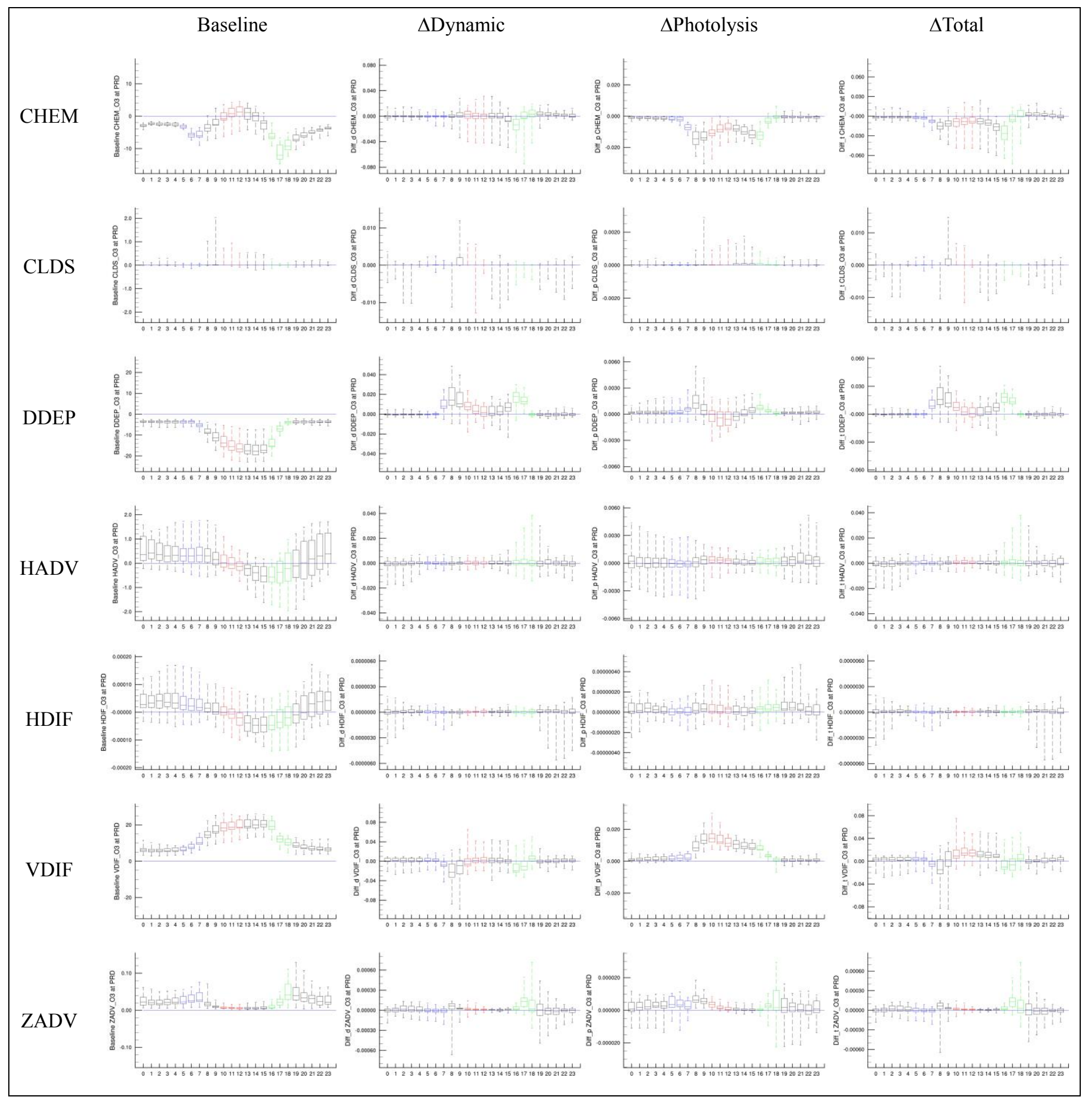

(a) January 


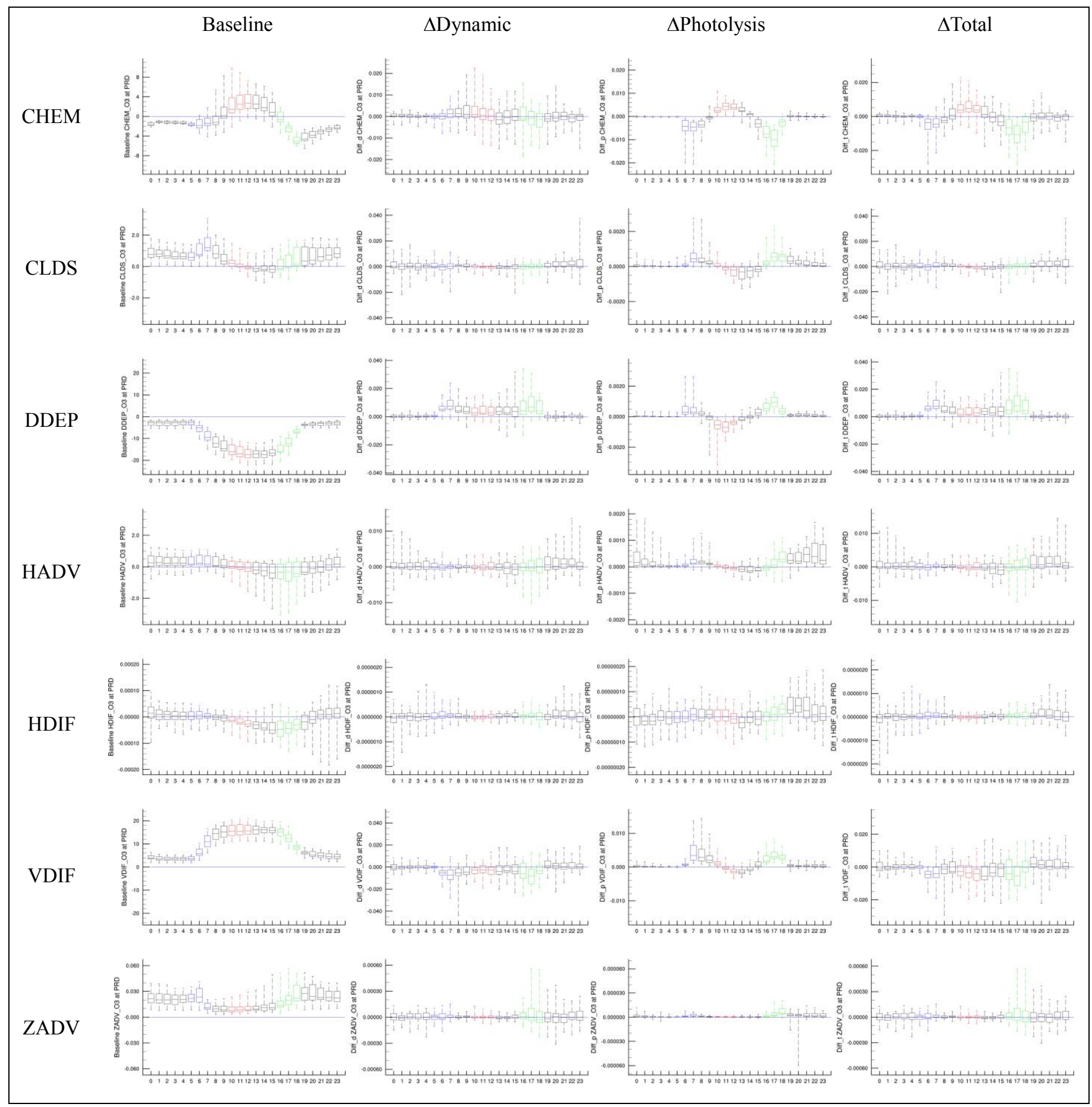

(b) July

Figure S3 same as Figure S1, but in PRD 


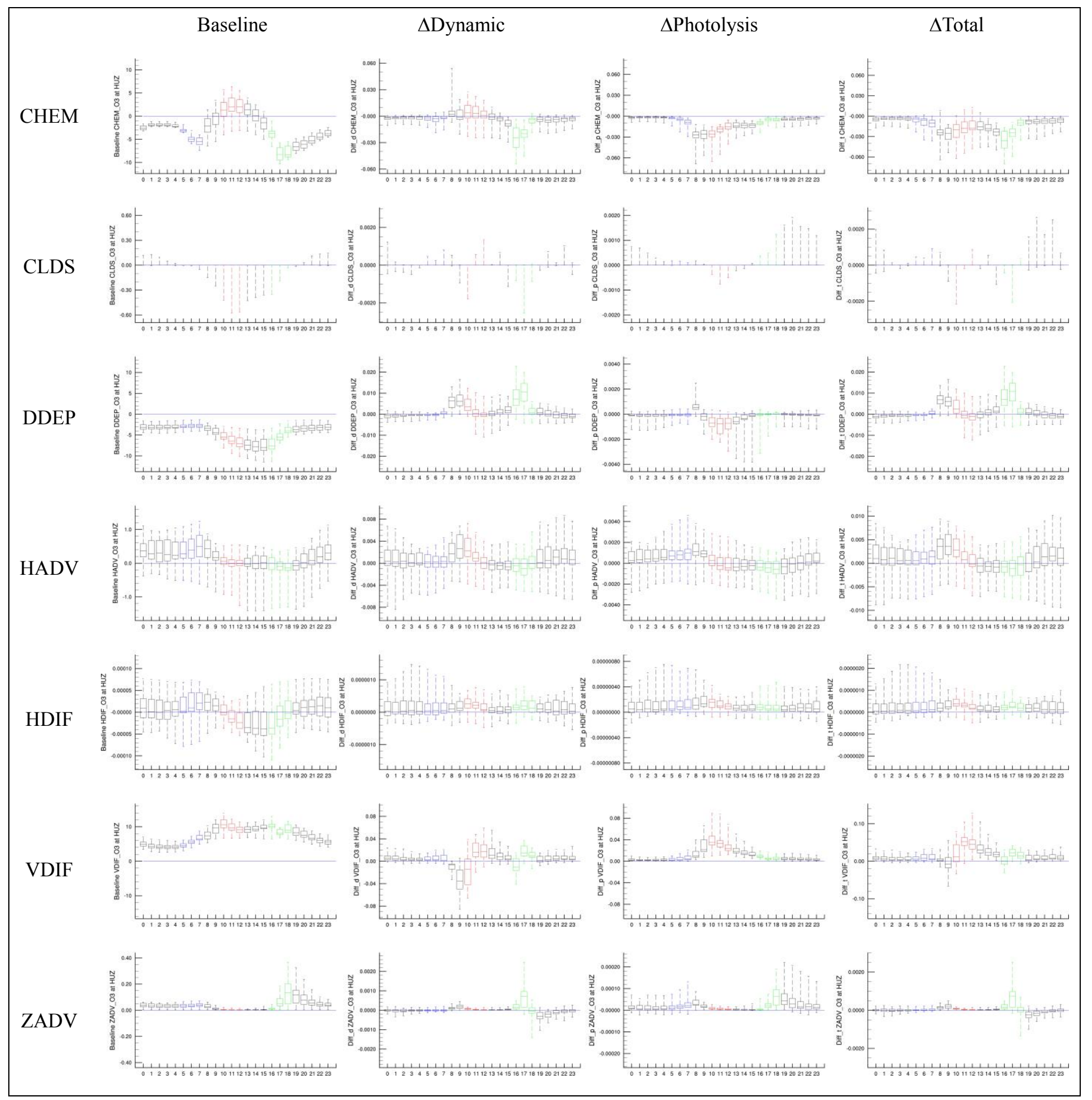

(a) January 


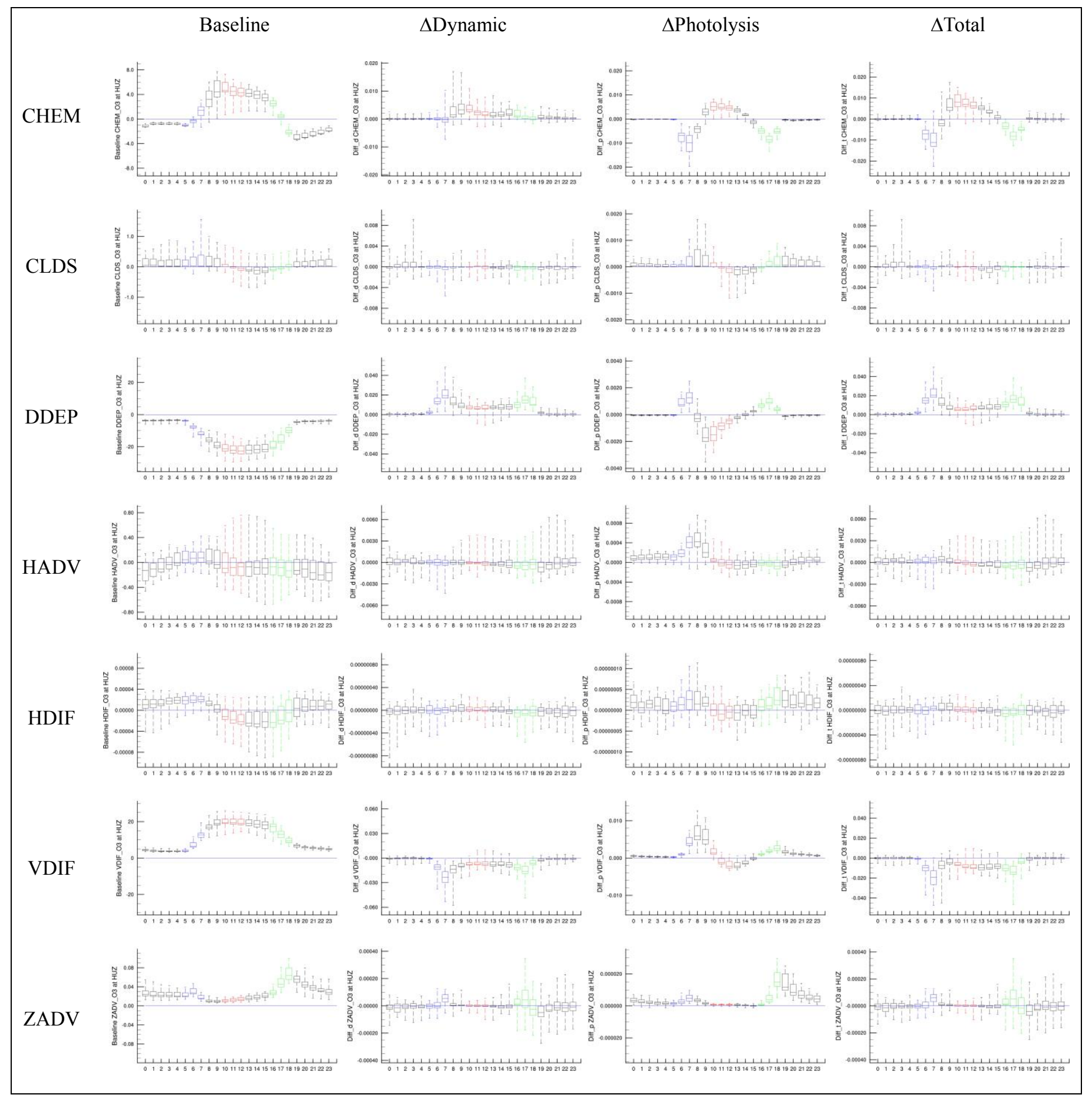

(b) July

Figure S4 same as Figure S1, but in HUZ 


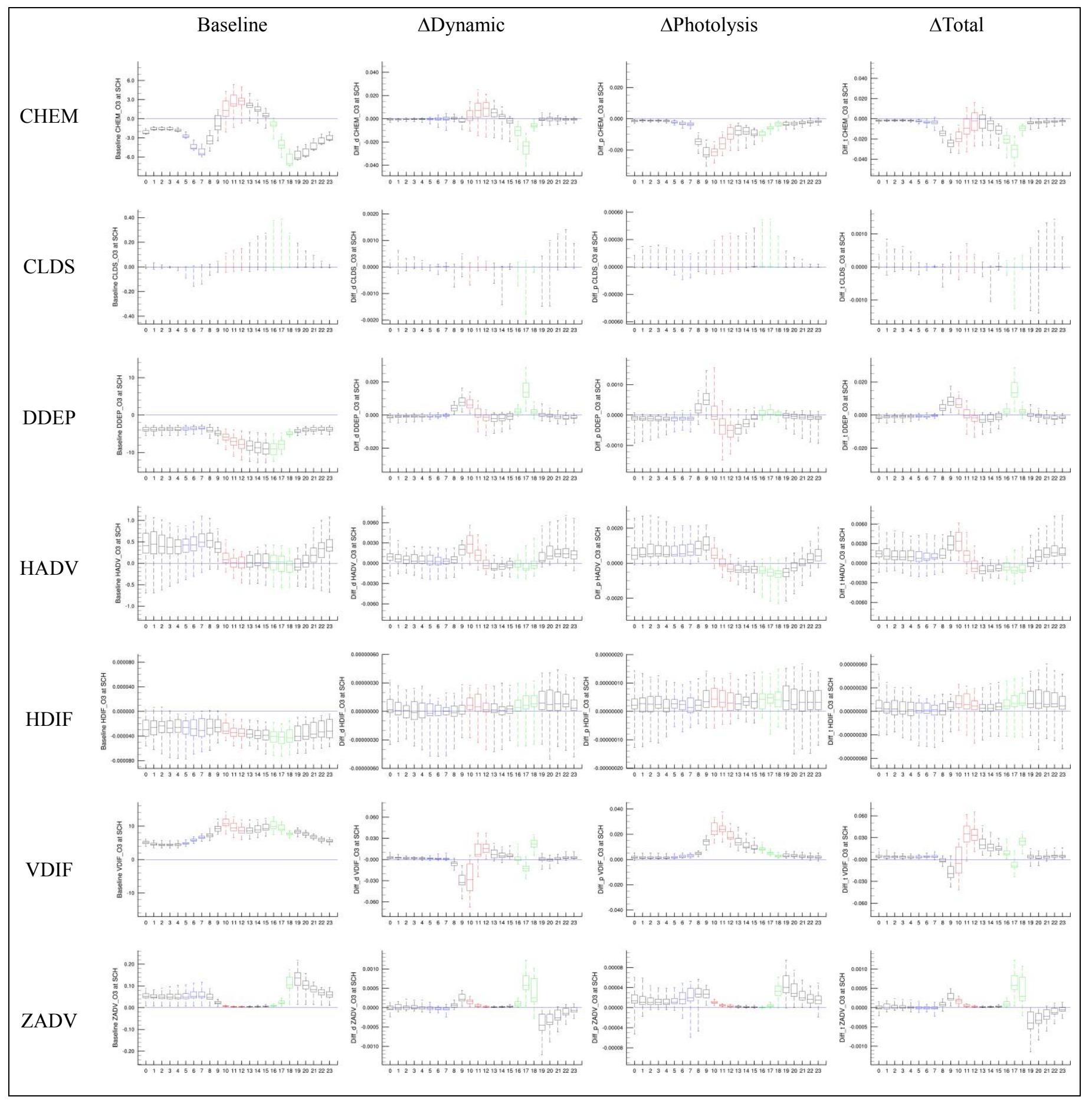

(a) January 


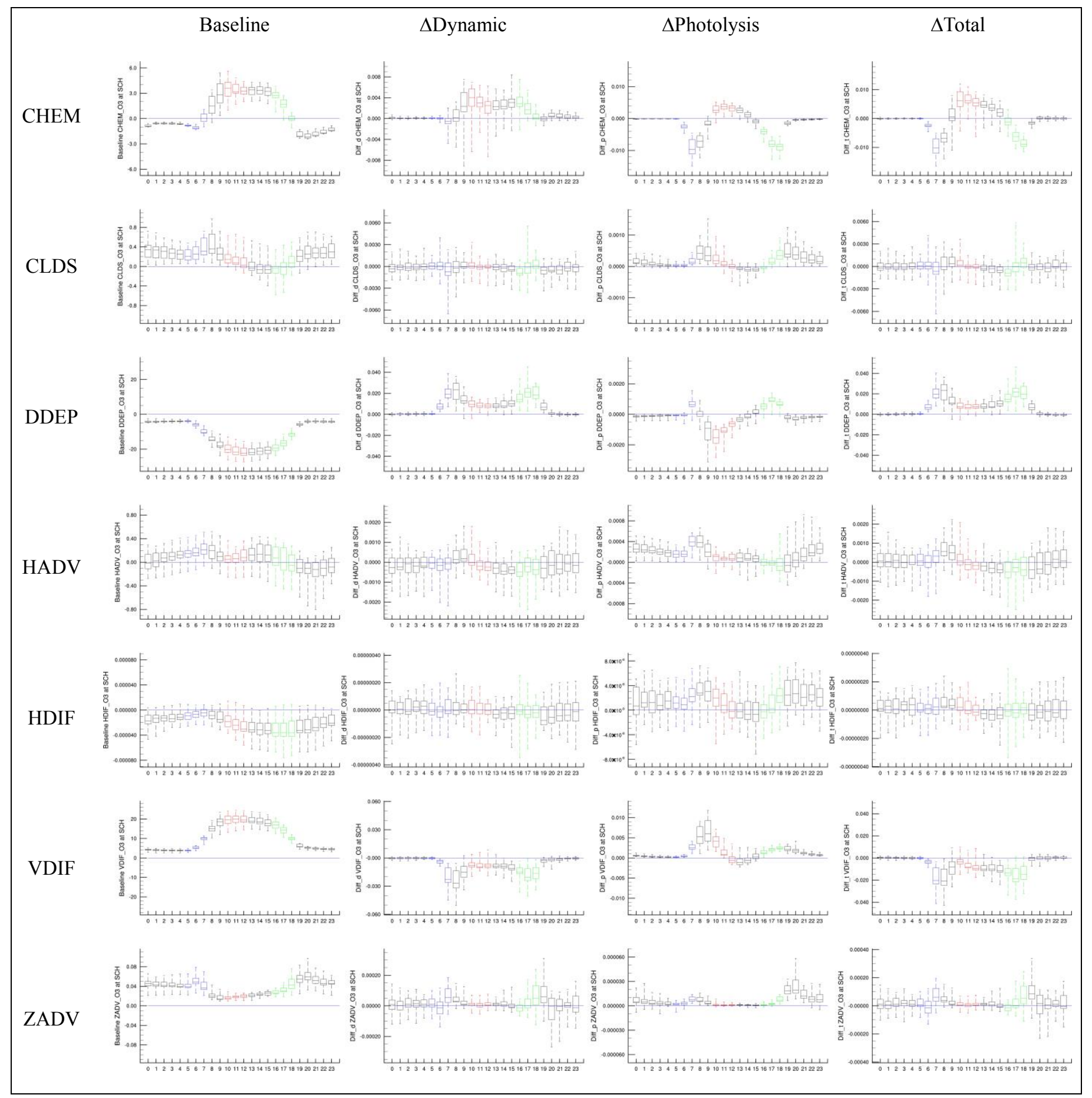

(b) July

Figure S5 same as Figure S1, but in $\mathrm{SCH}$ 


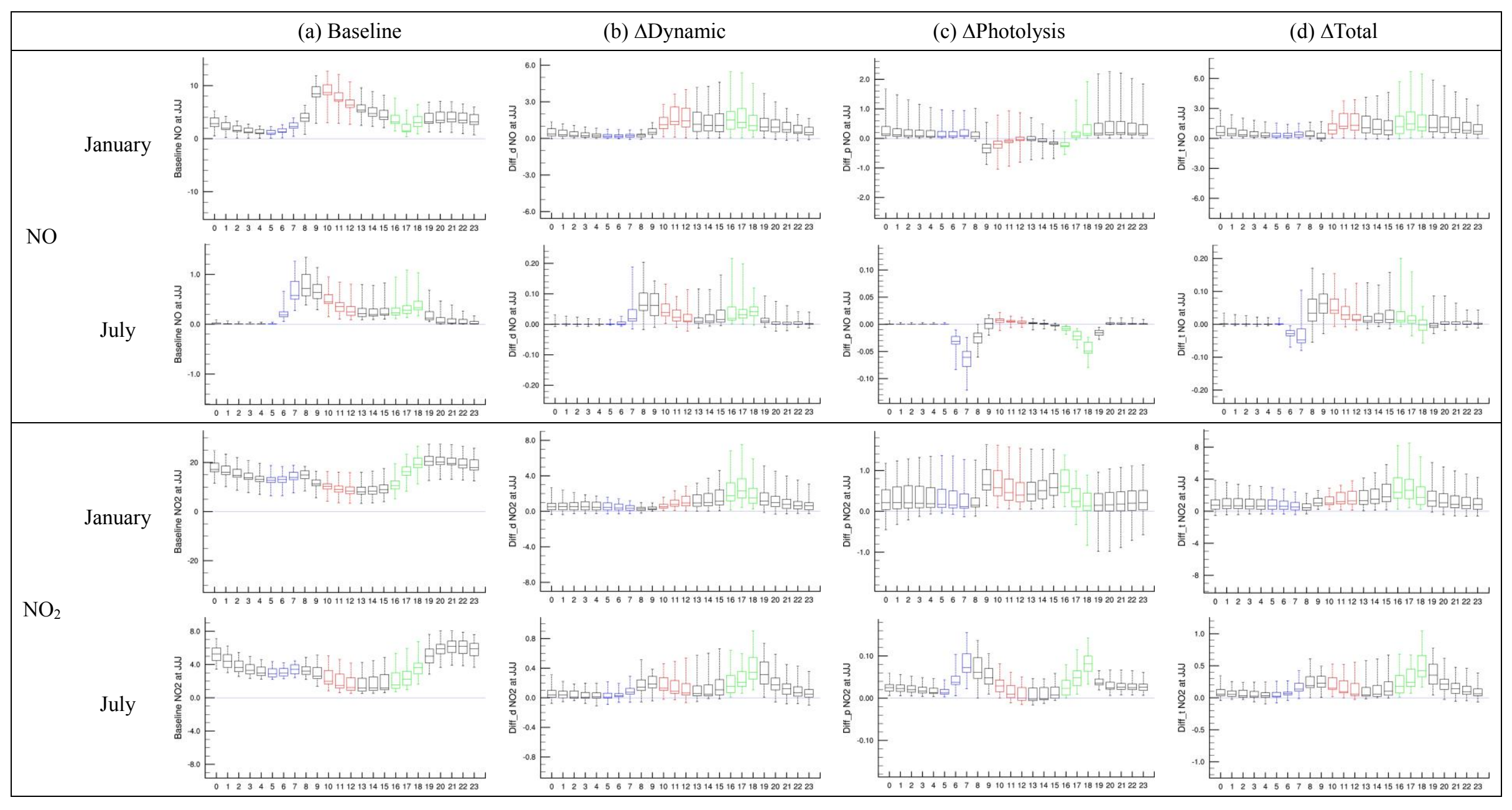

Figure S6 Diurnal variation of surface $\mathrm{NO}$ and $\mathrm{NO}_{2}$ concentrations and their response to ADE in JJJ (Baseline is the simulated NOX in SimBL, unit: ppb; b. $\Delta$ Dynamic is the difference in the NOx concentration between SimSF and SimNF, unit: ppb; c. $\Delta$ Photolysis is the difference in the NOX concentration between SimNF and SimBL, unit: ppb; d. $\triangle$ Total is the difference in the NOx concentration between SimSF and SimBL, unit: ppb) 


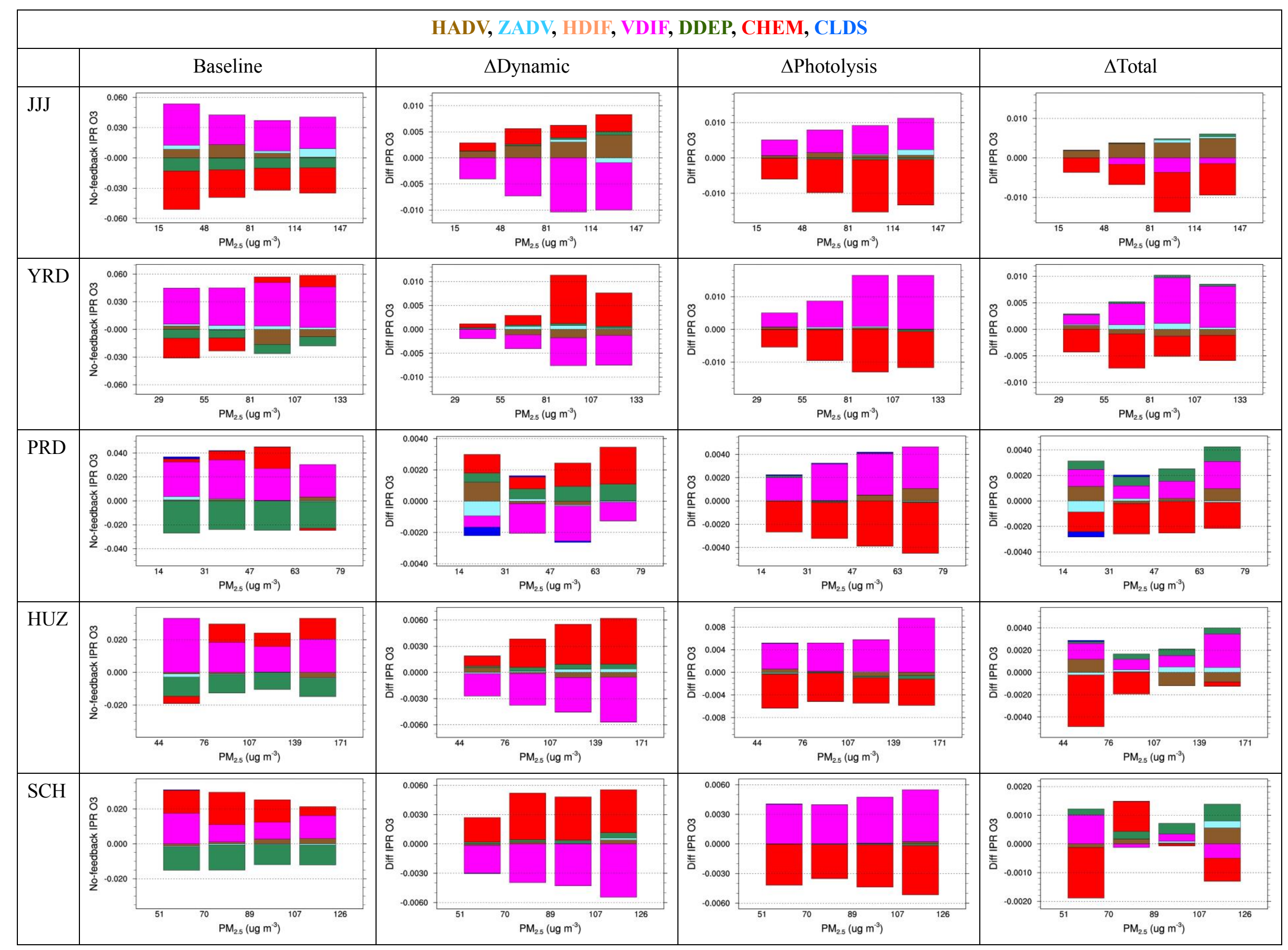

(a) January 


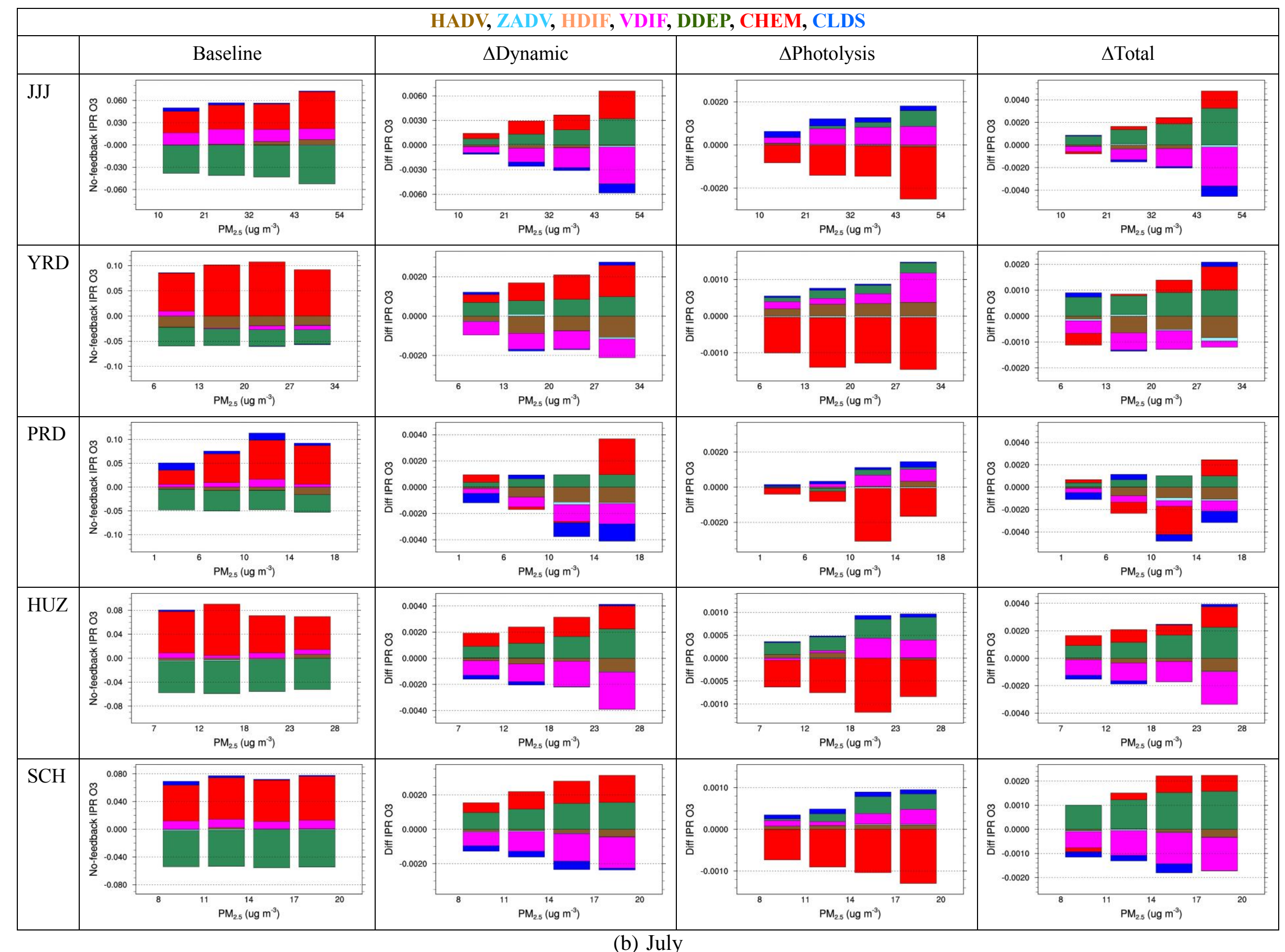

Figure $\mathrm{S} 7$ Integrated process contributions to daytime near-ground-level $\mathrm{O}_{3}$ under different $\mathrm{PM}_{2.5}$ level in 5 regions (between the ground and $350 \mathrm{~m}$ 
AGL, model layer 1-5; a. Baseline is the normalized IPRs in SimBL, unit: hr ${ }^{-1}$; b. $\Delta$ Dynamic is the difference in normalized IPRs between SimSF and SimNF, unit: $\mathrm{hr}^{-1} ; \mathrm{d}$. $\Delta$ Photolysis is the difference in normalized IPRs between SimNF and SimBL, unit: $\mathrm{hr}^{-1}$; c. $\Delta$ Total is the difference in normalized IPRs between SimSF and SimBL, unit: $\mathrm{hr}^{-1}$ ) 


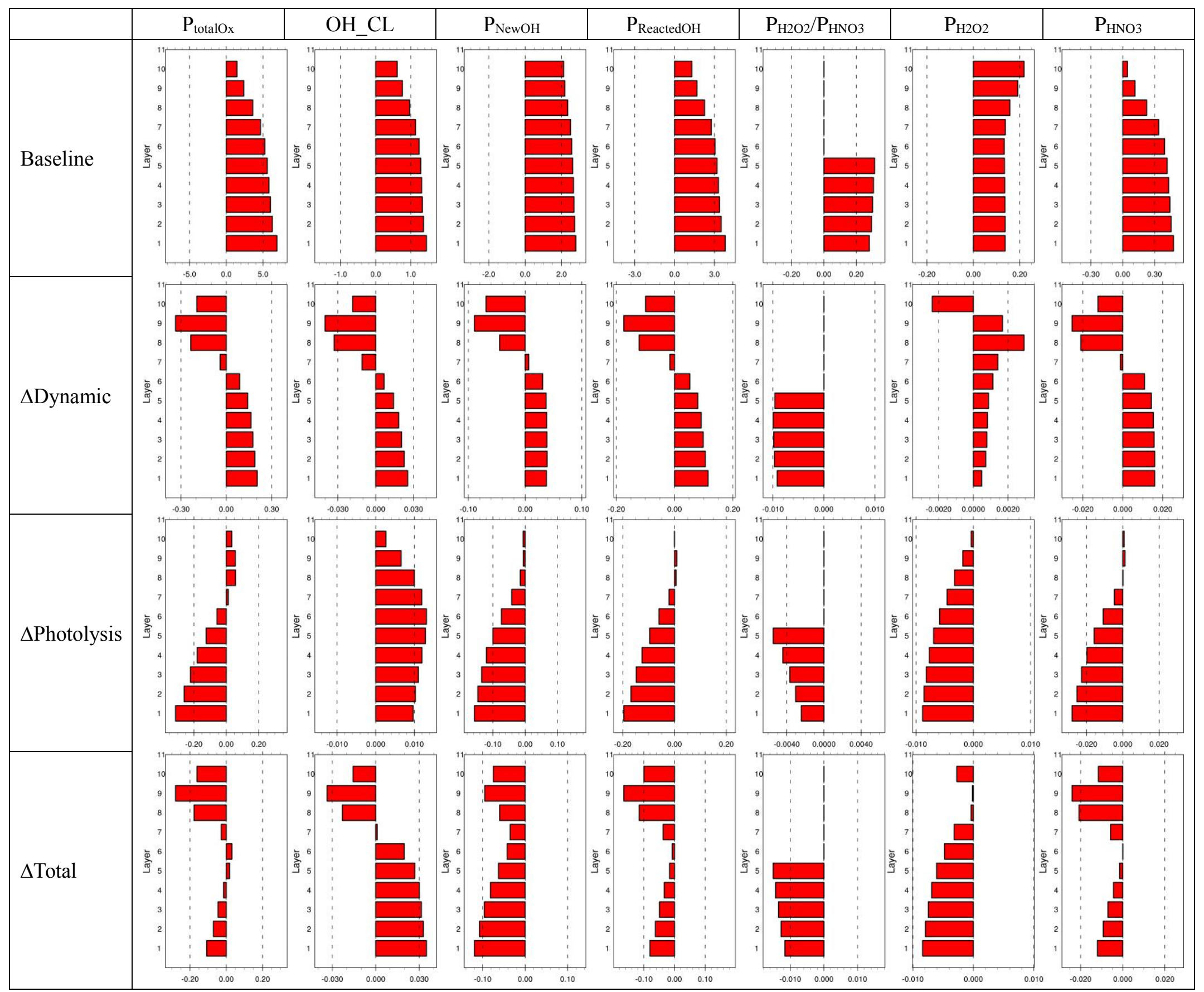

(a) January 


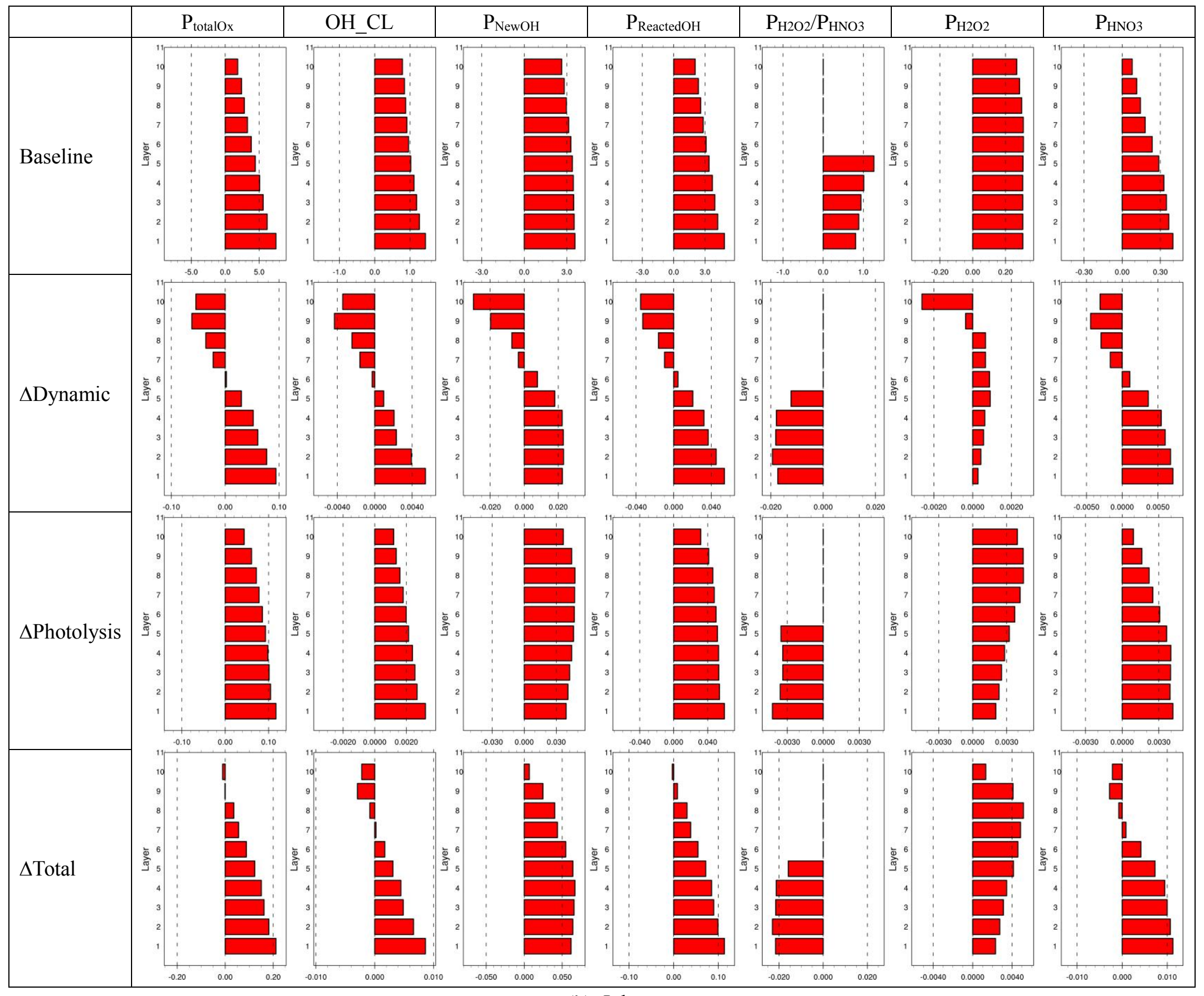

(b) July 
Figure S8 Vertical profile of integrated reaction rates in YRD at noon (a: January; b: July; full-layer heights above ground are 40, 96, 160, 241, 355, 503, 688, 884, 1100, 1357m; Baseline is the simulation in SimBL; $\triangle$ Dynamic is the difference between SimSF and SimNF; $\Delta$ Photolysis is the difference between SimNF and SimBL; $\Delta$ Total is the difference between SimSF and SimBL; $\mathrm{P}_{\text {totalOx }}$ is total $\mathrm{O}_{\mathrm{x}}$ production rate, unit: $\mathrm{ppb}$ hr ${ }^{-1}$; OH CL is OH chain length; $\mathrm{P}_{\mathrm{NewOH}}$ is the production rate of new $\mathrm{OH}$, unit: $\mathrm{ppb} \mathrm{hr}{ }^{-1}$; $\mathrm{P}_{\text {ReactedOH }}$ is the production rate of reacted $\mathrm{OH}$, unit: $\mathrm{ppb} \mathrm{hr}^{-1}$; $\mathrm{P}_{\mathrm{H} 2 \mathrm{O} 2}$ is the production rate of $\mathrm{H}_{2} \mathrm{O}_{2}$, unit: $\mathrm{ppb}^{-1}$; $\mathrm{P}_{\mathrm{HNO}}$ is the production rate of $\mathrm{HNO}_{3}$, unit: $\mathrm{ppb} \mathrm{hr}{ }^{-1}$; the ratio of $\mathrm{P}_{\mathrm{H} 2 \mathrm{O} 2} / \mathrm{P}_{\mathrm{HNO} 3}$ is only shown for layer 1-5) 


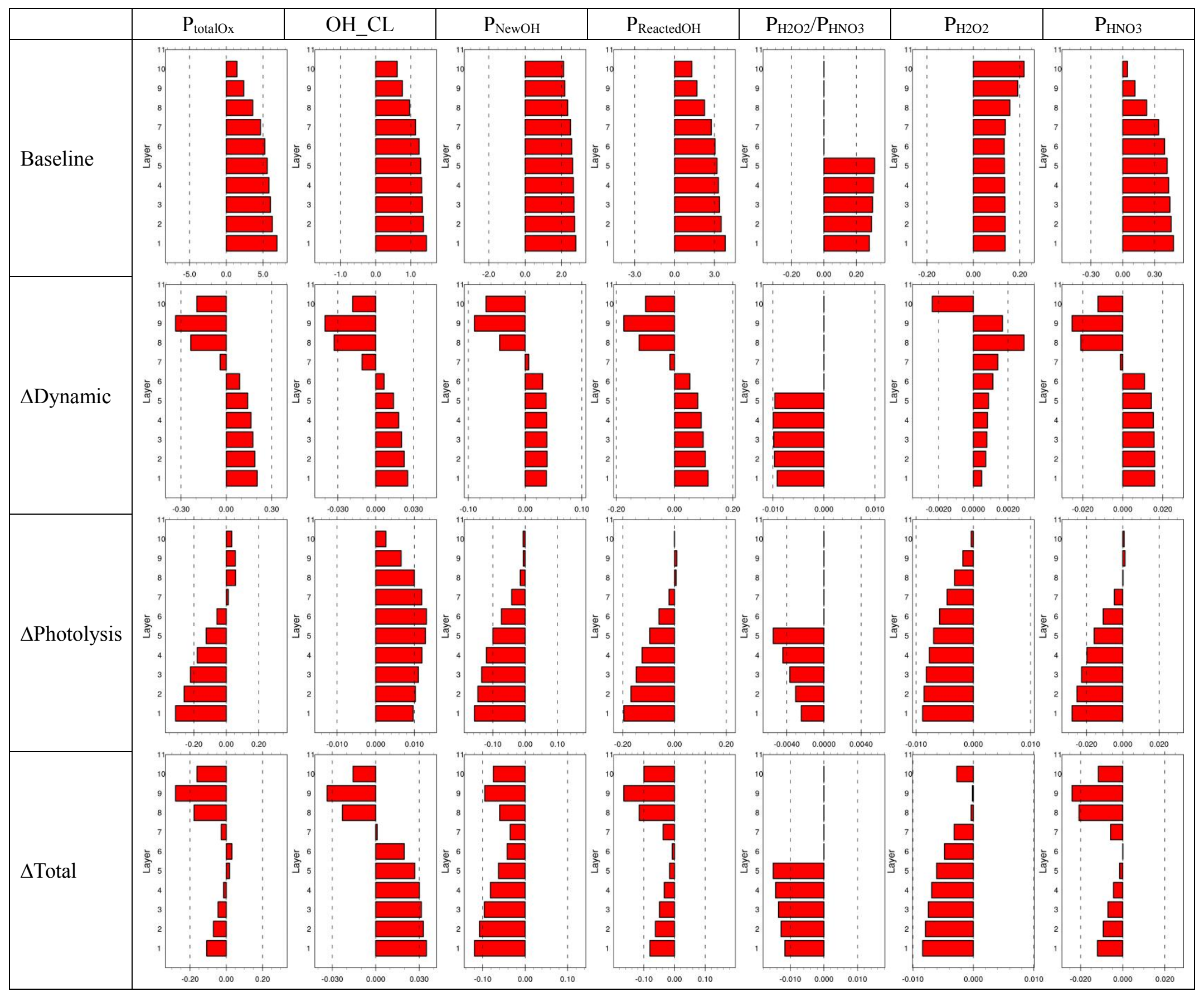

(a) January 


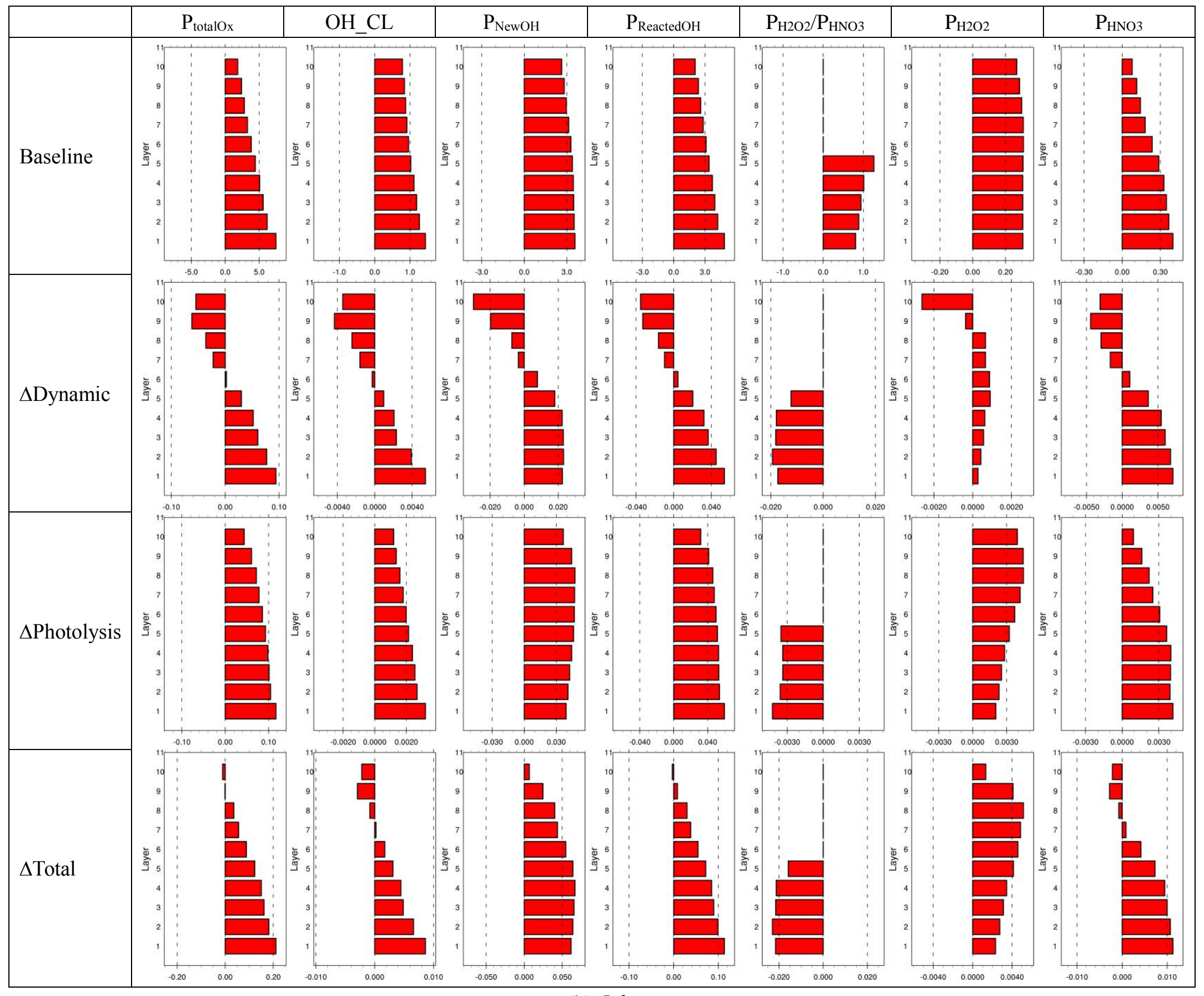

(b) July 
Figure S9 Same as Figure S8, but in PRD 


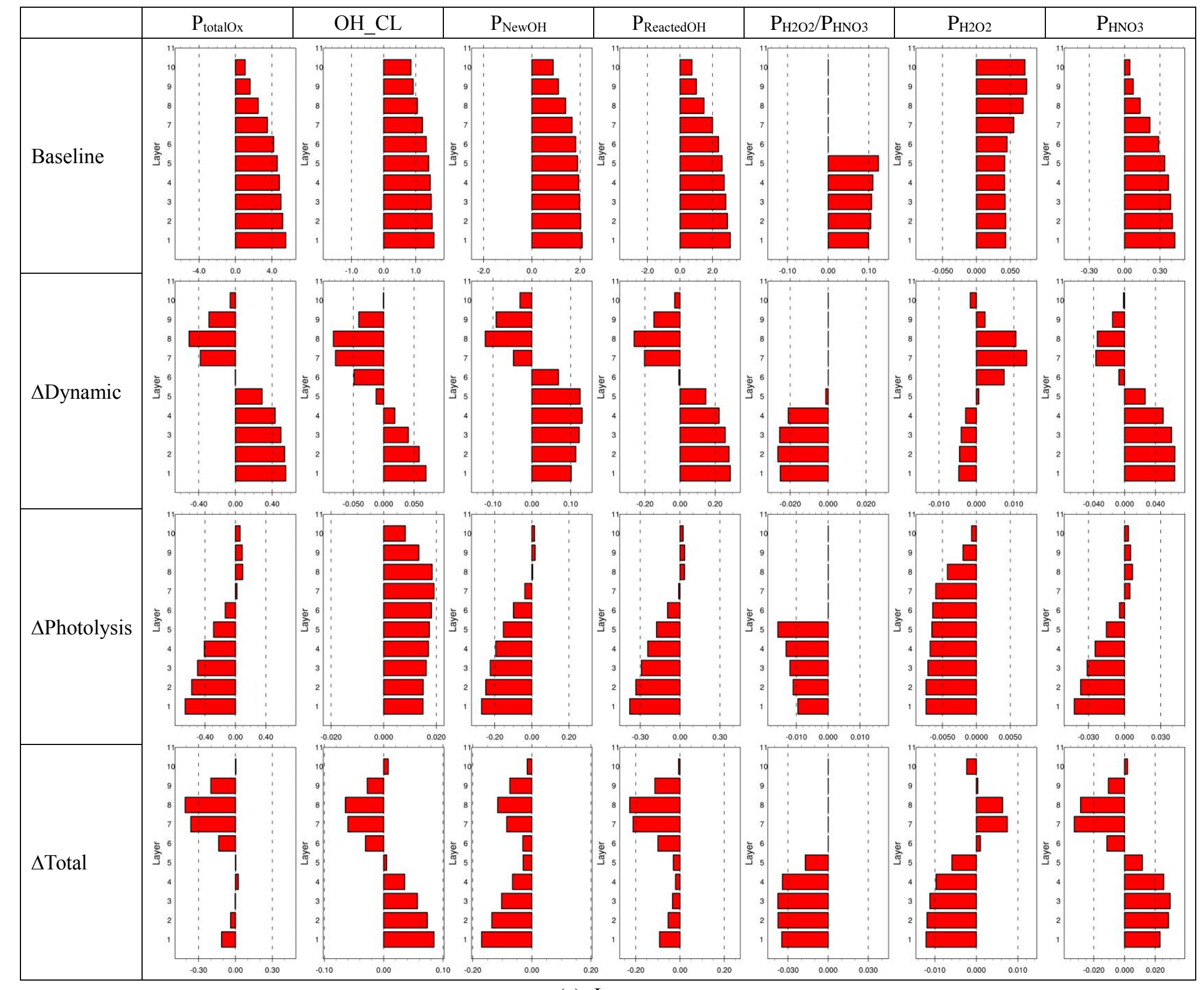

(a) January 


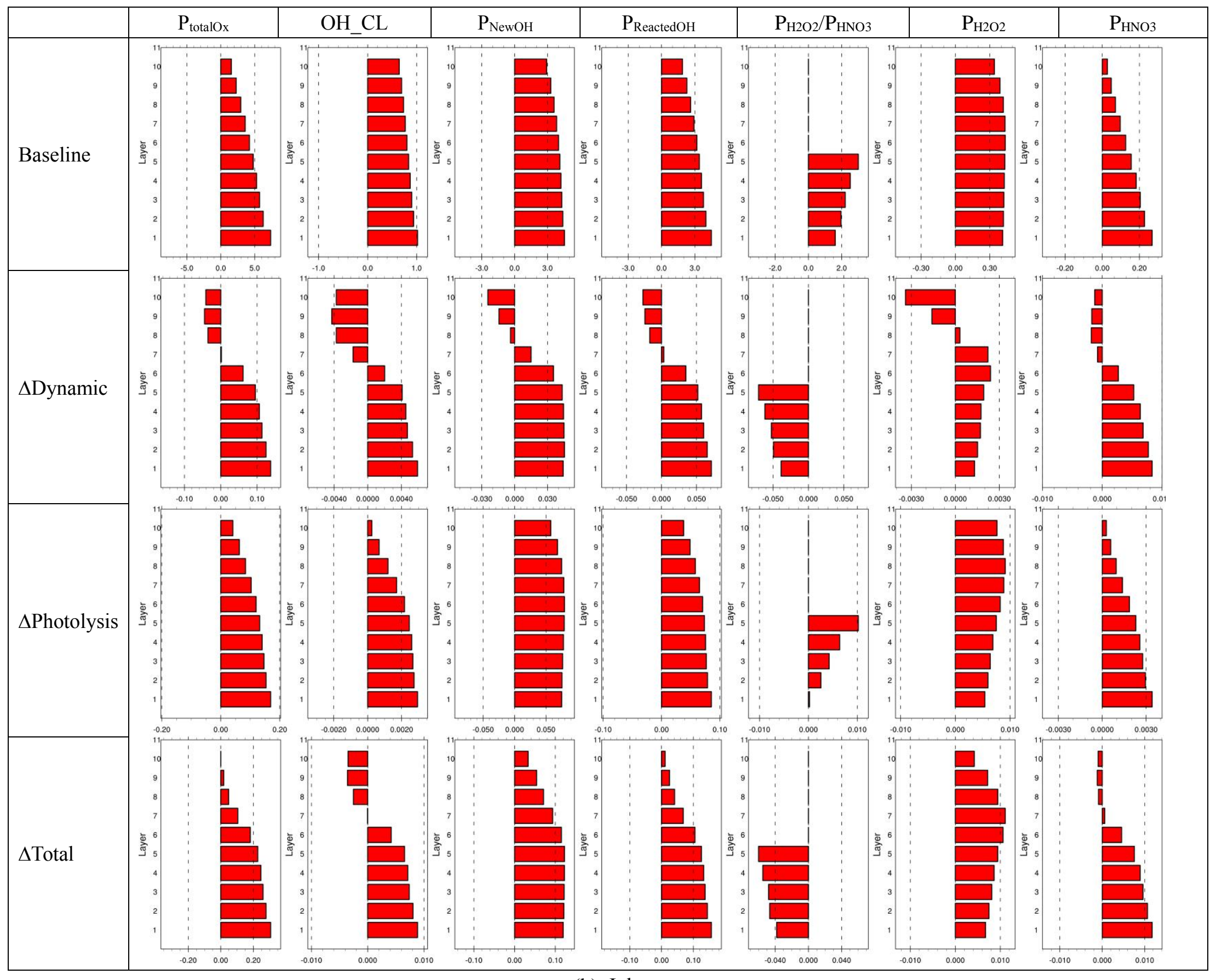

(b) July 
Figure S10 Same as Figure S8, but in HUZ 


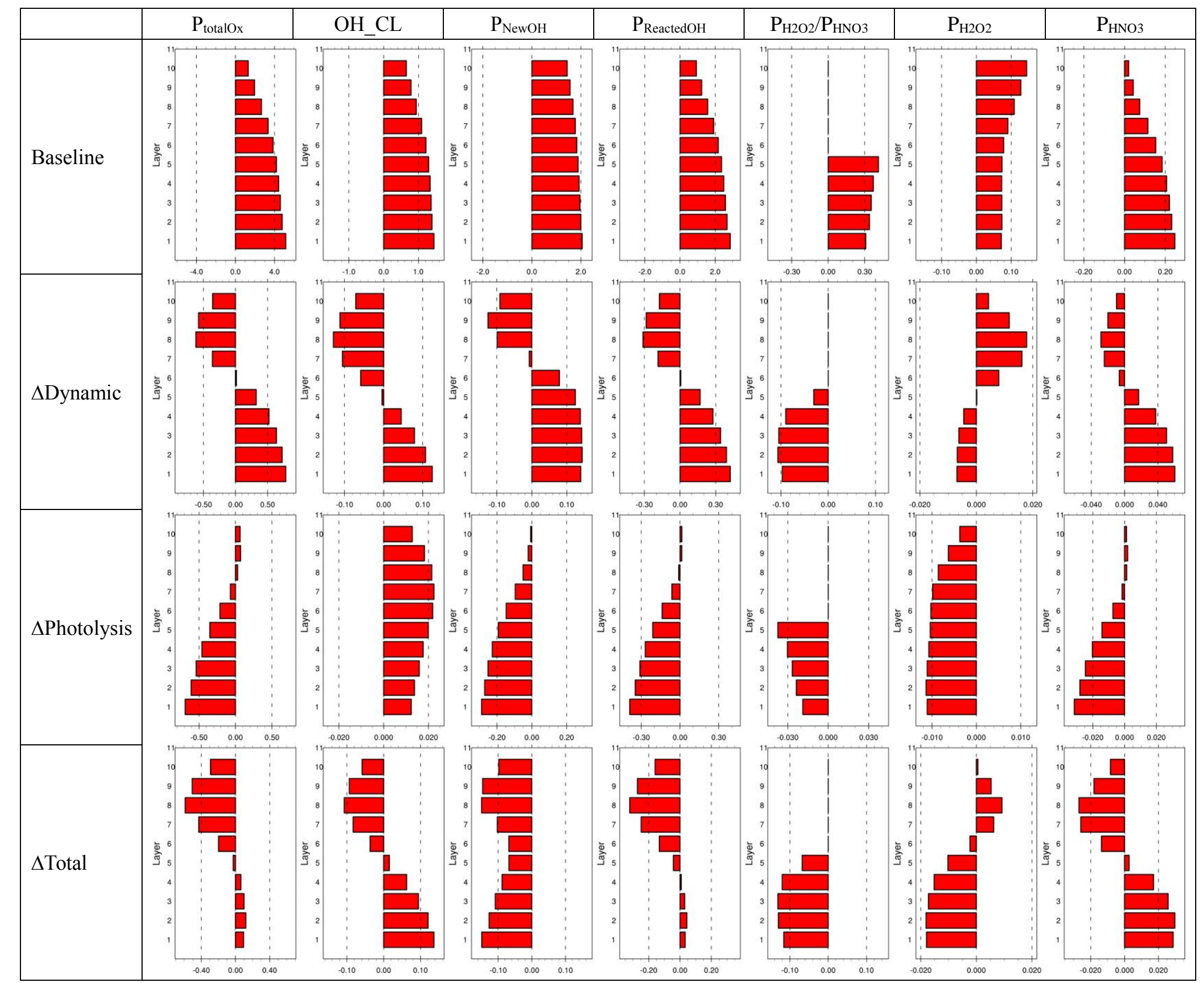

(a) January 


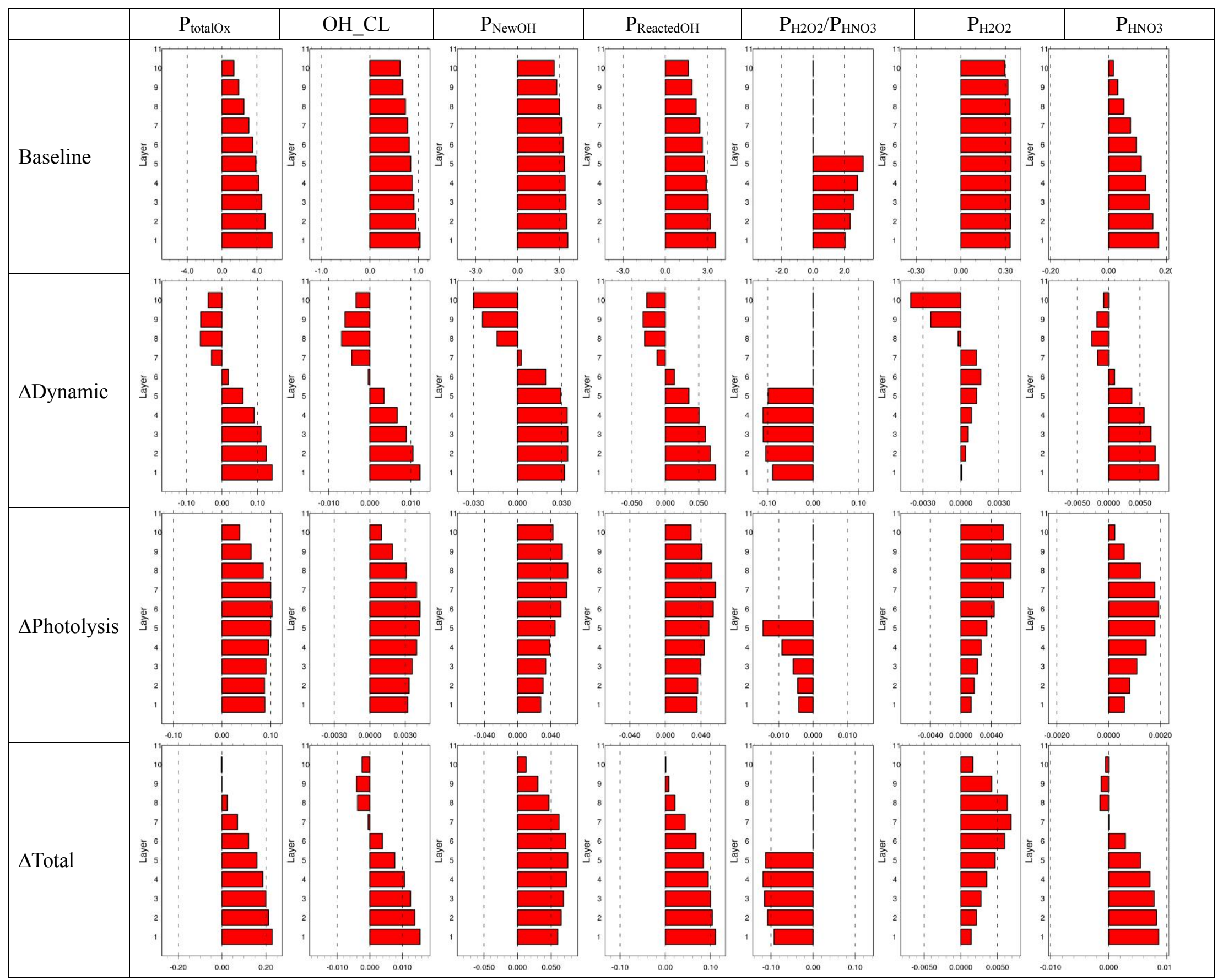

(b) July 
Figure S11 Same as Figure S8, but in SCH 